\title{
Acute and chronic effects of troglitazone (CS-045) on isolated rat ventricular cardiomyocytes
}

\author{
M. Bähr ${ }^{1}$, M.Spelleken ${ }^{1}$, M. Bock ${ }^{1}$, M.von Holtey ${ }^{1}$, R. Kiehn ${ }^{2}$, J. Eckel ${ }^{1}$ \\ ${ }^{1}$ Laboratory of Molecular Cardiology, Diabetes Research Institute, Düsseldorf, Germany \\ ${ }^{2}$ Sankyo Europe, Düsseldorf, Germany
}

\begin{abstract}
Summary Freshly isolated and primary cultured adult rat cardiomyocytes were used to elucidate the mechanism of action of the new oral antidiabetic agent ( \pm -5-[4-(6-hydroxy-2, 5, 7, 8-tetramethyl-chroman-2-yl-methoxy)benzyl]-2,4-thiazolidinedione (troglitazone) on the heart. Interaction with protein kinase $\mathrm{C}(\mathrm{PKC})$ and regulation of glucose transport were evaluated as possible sites of drug action. Acute treatment $(30 \mathrm{~min})$ of cardiomyocytes with troglitazone did not affect the phorbolester-induced membrane association of PKC-delta and PKC-epsilon, which represent the major isoforms present in these cells. However, under these conditions the phorbolester-mediated increase in membrane associated PKC activity was inhibited by $43 \pm 4 \%(n=4)$ without affecting the basal distribution of PKC activity. In contrast to these findings, troglitazone had no acute effect on basal or insulin-stimulated glucose transport in freshly isolated cardiomyocytes; even after $120 \mathrm{~min}$ treatment an unaltered release of lactate was determined in the presence of the drug. After
\end{abstract}

$20 \mathrm{~h}$ in serum-free culture troglitazone induced a dose-dependent increase in 2-deoxyglucose uptake reaching a 40 -fold stimulation at $5 \mu \mathrm{mol} / \mathrm{l}$. This was paralleled by a dose-dependent increase of glucose transporter-1 (GLUT1) and GLUT4 protein expression to $320 \pm 80$ and $156 \pm 15 \%$ of control, respectively. In addition, chronic exposure to troglitazone increased the GLUT4 abundance in a plasma membrane fraction about twofold. These data show that troglitazone exerts multiple effects on cardiomyocytes involving inhibition of $\mathrm{PKC}$ and regulation of glucose transporter expression and distribution. We suggest that an increased glucose supply may be beneficial for the diabetic heart and that modulation of PKC-activity could be relevant for improving insulin action in muscle tissue. [Diabetologia (1996) 39: 766-774]

Keywords Troglitazone (CS-045), cardiomyocytes, cell culture, glucose transport, protein kinase C.
Troglitazone (CS-045) is a new oral hypoglycaemic agent belonging to the thiazolidinedione family of compounds that is structurally unrelated to sulphonylureas or biguanides [1]. A number of studies in

Received: 5 July 1995 and in revised form: 20 December 1995

Corresponding author: Professor Dr. Jürgen Eckel, Diabetes Research Institute, Auf'm Hennekamp 65, D-40225 Düsseldorf, Germany

Abbreviations: PDD, 4-alpha-phorbol 12, 13-didecanoate; PMA, phorbol 12-myristate 13-acetate; PKC, protein kinase C; GLUT, glucose transporter isoform; Hepes, N-2-hydroxyethylpiperazine-N-2-ethanesulphonic acid. genetic $[2,3]$ and nongenetic [4] rodent models of insulin resistance indicate that troglitazone increases insulin sensitivity and responsiveness [2] and is able to correct hyperglycaemia, hyperinsulinaemia and hypertriglyceridaemia to near-normal values $[2,3]$. Further, the compound reduces the elevated blood pressure associated with insulin resistance to the normal range $[4,5]$. Clinical studies on subjects with non-insulin-dependent diabetes mellitus (NIDDM) [6] have confirmed these animal data and showed that administration of troglitazone reduces insulinaemia, improves fasting and postprandial glycaemia, decreases insulin resistance and the level of non-esterified fatty acids [7]. In a recent report Olefsky and co-workers 
[8] showed that troglitazone decreases insulin resistance in non-diabetic obese patients making the drug potentially important for preventing NIDDM.

The precise mechanism of troglitazone action has remained incompletely understood. Data available so far suggest that the drug exerts multiple cellular effects involving both a potentiation of insulin action $[2,9]$ and direct, insulin mimicking effects in different target tissues $[10,11]$. Increased tyrosine kinase activity in skeletal muscle of insulin-resistant animals has been observed after treatment with troglitazone [12] or the thiazolidinedione compound pioglitazone [13]. This may result from the potency of troglitazone to ameliorate serine/threonine kinase-mediated inhibitory effects on insulin receptor tyrosine kinase. In agreement, Kellerer et al. [9] recently showed that troglitazone antagonizes the glucose-induced inhibition of insulin receptor kinase in rat-1 fibroblasts, a process presumably mediated by protein kinase $\mathrm{C}$ (PKC) [9]. Reported direct actions of troglitazone include an enhanced glycogen synthase $\mathrm{I}$ activity in BC3H-1 myocytes [10], an inhibition of gluconeogenesis in HepG2 cells [10], and an increased production of fructose-2,6-bisphosphate in rat hepatocytes [11]. A large increase in basal glucose uptake and an increased protein expression of GLUT1 and GLUT4 have been observed in 3T3-L1 adipocytes in response to troglitazone [14].

In contrast to liver and fat, no information is presently available concerning the cardiac action of troglitazone at the cellular or molecular level. This issue needs specific attention, since 1) ischaemic heart disease represents a major complication in diabetes [15] and an increased glucose supply may sustain both function and viability of the cardiomyocyte; 2) troglitazone may improve insulin action on cardiac glucose uptake or directly regulate this process. We have recently reported that activation of PKC in freshly isolated cardiomyocytes results in a desensitization of insulin-stimulated glucose transport [16]. Using this cellular system we have investigated whether troglitazone interferes with PKC activation in the cardiac cell. Further, by using primary cultured adult cardiomyocytes $[17,18]$ we explored the potency and the mechanisms of troglitazone in directly modulating cardiac metabolism at the level of the glucose transporters GLUT1 and GLUT4.

\section{Materials and methods}

Chemicals. 3-O- $\left[{ }^{14} \mathrm{C}\right] \mathrm{Methyl}-\mathrm{D}-\mathrm{glucose}(54 \mathrm{mCi} / \mathrm{mmol}), \quad \mathrm{L}-[1-$ $\left.{ }^{14} \mathrm{C}\right]$ glucose $\quad(55 \mathrm{mCi} / \mathrm{mmol}), \quad 2-D e o x y-D-\left[1-{ }^{14} \mathrm{C}\right]$ glucose $(55 \mathrm{mCi} / \mathrm{mmol})$ and ${ }^{125} \mathrm{I}$-labelled protein $\mathrm{A}(30 \mathrm{mCi} / \mathrm{mg})$ were purchased from Amersham (Braunschweig, Germany). [Gamma- ${ }^{32}$ P]ATP $(6000 \mathrm{Ci} / \mathrm{mmol})$ was obtained from New England Nuclear (Dreieich, Germany). Collagenase (EC 3.4.24.3) was a product of Serva (Heidelberg, Germany). Fetal calf serum, Dulbecco's modified Eagle's medium (DMEM) and non-essential amino acids were purchased from Gibco (Eggenstein, Germany). Ham's F12 medium was obtained from ICN (Meckenheim, Germany). Laminin was from Beckton Dickinson (Heidelberg, Germany). Phorbol 12-myristate 13-acetate (PMA), 4-alpha-phorbol 12,13-didecanoate (PDD), phosphatidylserine, 1,2-diolein and histone III-S were from Sigma (München, Germany). The polyclonal GLUT1- and GLUT4antisera were supplied by Calbiochem (Bad Soden, Germany). Isoform-specific PKC rabbit polyclonal antisera and the corresponding peptides (amino acid sequence 662-673 for PKC-delta and 726-737 for PKC-epsilon) were purchased from Boehringer (Mannheim, Germany). Troglitazone was provided by Sankyo (Tokyo, Japan). PKC from rat brain and bisindolylmaleimide I were obtained from Calbiochem. All other chemicals were of the highest grade commercially available.

Isolation and culture of adult cardiac myocytes. Male Wistar rats weighing $280-320 \mathrm{~g}$ were used in all experiments. Calcium-tolerant myocytes were isolated by perfusion of adult rat heart with collagenase, as outlined previously [19]. Cell culture was performed using a modification of our earlier published procedure [17]. Briefly, isolated cells were suspended in culture medium (DMEM/Ham's F12, $1: 1,4 \%$ fetal calf se$\mathrm{rum}, 100 \mu \mathrm{g} / \mathrm{ml}$ streptomycin, $100 \mathrm{U} / \mathrm{ml}$ penicillin $\mathrm{G}, 10 \mathrm{mmol} / \mathrm{l}$ Hepes, non-essential amino acids, $25.3 \mathrm{mmol} / \mathrm{l}$ D-glucose, $1.7 \times 10^{-11} \mathrm{~mol} / 1$ insulin) to give a final cell concentration of $1 \times 10^{5}$ cells $/ \mathrm{ml}$ and were then plated on culture dishes which had been precoated with laminin. Coating was performed by incubating the culture dishes for $60 \mathrm{~min}$ at room temperature with $1 \mathrm{ml}$ serum-free culture medium containing $20 \mu \mathrm{g}$ laminin. After an attachment period of $3 \mathrm{~h}$ the cells were washed and culture was then continued in the above-mentioned medium containing $17.5 \mathrm{mmol} / \mathrm{l} \mathrm{D}$-glucose for the indicated times. Five hours before the transport experiment this medium was replaced by culture medium containing $7.8 \mathrm{mmol} / \mathrm{l} \mathrm{D}$-glucose and no insulin $[17,18]$.

Preparation of cytosol and membrane fractions. Cardiomyocytes $\left(5 \times 10^{5}\right.$ cells $\left./ 0.5 \mathrm{ml}\right)$ were exposed for $30 \mathrm{~min}$ to either PDD or PMA in the absence or presence of troglitazone. Cells were then homogenized in a buffer containing $20 \mathrm{mmol} / 1 \mathrm{He}-$ pes, $5 \mathrm{mmol} / 1 \mathrm{EGTA}, 0.25 \mathrm{mmol} / 1$ sucrose, $5 \mathrm{mmol} / 1 \mathrm{DTT}, 1 \mathrm{~g} / 1$ BSA and $50 \mu \mathrm{g} / \mathrm{ml}$ leupeptin by sonication (five times for $10 \mathrm{~s}$ ) followed by $9 \times 4$ strokes in a glass potter homogenizer. The whole homogenate was centrifuged for $45 \mathrm{~min}$ at $100,000 \times g$ and the supernatant was considered as the cytosolic fraction. The pellet was solubilized for $30 \mathrm{~min}$ in homogenizing buffer containing $0.4 \%$ Triton X-100 and centrifuged at $10,000 \times g$ for $10 \mathrm{~min}$. The supernatant was then saved as the membrane fraction. Both cytosolic and membrane fractions were mixed with Laemmli electrophoresis buffer prior to Western blot analysis of PKC.

Protein kinase $C$ assay. Cytosolic and membrane fractions were applied to DEAE-cellulose columns, which were washed with $2.5 \mathrm{ml}$ of a buffer containing $20 \mathrm{mmol} / \mathrm{l}$ Tris $/ \mathrm{HCl}(\mathrm{pH} \mathrm{7.4})$, $2 \mathrm{mmol} / \mathrm{l}$ EDTA, $5 \mathrm{mmol} / 1 \mathrm{EGTA}$ and $2 \mathrm{mmol} / \mathrm{l} \mathrm{PMSF}$ PKC was eluted with the same buffer containing $100 \mathrm{mmol} / \mathrm{l} \mathrm{NaCl}$. PKC activity was then determined by measuring the $\mathrm{Ca}^{++}$and phospholipid-dependent transfer of ${ }^{32} \mathrm{P}$ from ${ }^{32} \mathrm{P}$-ATP to histone III-S. One hundred microlitres of the eluate was added to $150 \mu \mathrm{l}$ of a solution containing $20 \mathrm{mmol} / \mathrm{l} \mathrm{Tris} / \mathrm{HCl}(\mathrm{pH} \mathrm{7.5})$, $10 \mathrm{mmol} / \mathrm{l}$ magnesium acetate, $25 \mu \mathrm{g}$ histone III-S either in the absence or presence of $0.75 \mathrm{mmol} / 1 \mathrm{CaCl}_{2}, 12 \mu \mathrm{g}$ of phosphatidylserine and $1.6 \mu \mathrm{g}$ of 1,2 -diolein. The reaction was started by addition of $50 \mu \mathrm{mol} / 1$ ATP containing $5 \mu \mathrm{Ci}$ of ${ }^{32} \mathrm{P}$-ATP per assay and conducted for $30 \mathrm{~min}$ at room temperature. 
Histone was then precipitated by addition of ice-cold $25 \%$ trichloroacetic acid and separated by filtration on $0.45 \mu \mathrm{m}$ nitrocellulose filters. Filters were then counted by liquid scintillation. All data were corrected for phospholipid-independent kinase activity. Translocation of PKC activity was determined by measuring the ratio of membrane associated activity/total activity (total activity is cytosolic activity plus particulate activity).

Assay of 3-O-methylglucose transport and 2-deoxyglucose uptake. All transport experiments using freshly isolated cells were performed at $37^{\circ} \mathrm{C}$ in Hepes buffer (composition in $\mathrm{mmol} / 1: 130 \mathrm{NaCl}, 4.8 \mathrm{KCl}, 1.2 \mathrm{KH}_{2} \mathrm{PO}_{4}, 1 \mathrm{MgCl}_{2}, 1 \mathrm{CaCl}_{2}, 25$ Hepes, $5 \mathrm{D}$-glucose, $20 \mathrm{~g} / \mathrm{l}$ bovine serum albumin, $\mathrm{pH} 7.4)$. The reaction was started by pipetting a $50-\mu$ l aliquot of the cell suspension to $50 \mu$ l of Hepes buffer containing 3-O- $\left[{ }^{14} \mathrm{C}\right]$ methylD-glucose (final concentration $100 \mu \mathrm{mol} / \mathrm{l}$ ). Carrier-mediated glucose transport was then determined using a 10 -s assay period and $\mathrm{L}-\left[{ }^{14} \mathrm{C}\right]$ glucose in order to correct for simple diffusion, as described in earlier reports from this laboratory [16, 19]. Determinations of 2-deoxyglucose uptake were performed at $37^{\circ} \mathrm{C}$ in monolayer $\left(10^{5}\right.$ cells per dish) in culture medium containing $7.8 \mathrm{mmol} / 1$ glucose. 2 -Deoxy-D-[1- $\left.{ }^{14} \mathrm{C}\right]$ glucose $(0.4 \mu \mathrm{Ci}$ per dish, final concentration $7.3 \mu \mathrm{mol} / 1$ ) was added, and hexose uptake was assayed for $90 \mathrm{~min}$. Uptake was stopped by aspirating the medium and washing the dishes two times with cold PBS containing $25 \mu \mathrm{mol} / 1$ cytochalasin B. Cells were then dissolved in $1 \mathrm{~N} \mathrm{NaOH}$, and aliquots were taken for scintillation counting and protein determinations. Carrier-independent uptake was determined in parallel incubations using $\mathbf{L}-\left[{ }^{14} \mathrm{C}\right] \mathrm{glu}-$ cose instead of deoxyglucose and was subtracted from all determinations. Protein was determined using the Bio-Rad protein assay and bovine serum albumin as a standard. Lactate was determined photometrically [20] in separate cell cultures using aliquots of the cell supernatant.

Plasma membrane preparation. At the end of the culture period the cells were washed twice with TES buffer (composition in $\mathrm{mmol} / \mathrm{l}: 225$ sucrose, 1 EDTA, 20 Tris, $2.5 \mu \mathrm{g} / \mathrm{ml}$ leupeptin, $2.5 \mu \mathrm{g} / \mathrm{ml}$ pepstatin, $5 \mu \mathrm{g} / \mathrm{ml}$ aprotinin, $0.2 \mathrm{mmol} / 1$ phenylmethylsulfonyl fluoride, $\mathrm{pH} 7.4$ ). Cells were then scraped from the dishes using ice cold TES buffer and a rubber policeman, immediately frozen in liquid $\mathrm{N}_{2}$ and stored at $-70^{\circ} \mathrm{C}$. Crude membranes were then prepared according to our previously published protocols $[21,22]$. In brief, cells were incubated in hypotonic Tris buffer (composition: $10 \mathrm{mmol} / 1$ Tris, $5 \mu \mathrm{g} / \mathrm{ml}$ aprotinin, $2.5 \mu \mathrm{g} / \mathrm{ml}$ pepstatin, $2.5 \mu \mathrm{g} / \mathrm{ml}$ leupeptin, $0.2 \mathrm{mmol} / \mathrm{l}$ phenylmethylsulphonyl fluoride, $3.2 \mathrm{mmol} / 1$ dithiothreitol, $\mathrm{pH}$ 7.4) for $30 \mathrm{~min}$ and then homogenized in a Dounce homogenizer by nine strokes followed by sonication (six times for $10 \mathrm{~s}$ ) and additional nine strokes in the Dounce homogenizer. Sucrose was then added to give a final concentration of $0.25 \mathrm{~mol} / \mathrm{l}$, and the homogenate was centrifuged at $3000 \times g$ for $10 \mathrm{~min}$. The supernatant was then centrifuged at $200000 \times \mathrm{g}$ for $90 \mathrm{~min}$ in a Beckman Ti70 rotor to pellet the crude membrane fraction. After homogenization this material was either stored in aliquots at $-70^{\circ} \mathrm{C}$ or applied to a discontinuous gradient consisting of $0.57,0.72,1.07$ and $1.43 \mathrm{~mol} / 1 \mathrm{su}$ crose buffer and centrifuged at $40000 \times g$ for $16 \mathrm{~h}$. Membranes were harvested from each sucrose layer and stored at $-70^{\circ} \mathrm{C}$. As reported earlier [21], membranes recovered from the $0.57 \mathrm{~mol} / \mathrm{l}$ sucrose layer were enriched $6-7$ fold in $\mathrm{Na}^{+} / \mathrm{K}^{+}-\mathrm{AT}$ Pase activity and considered as a plasma membrane fraction.

Immunoblotting. Protein samples were separated by SDSPAGE using $10 \%$ gels and transferred to nitrocellulose filters in a semi-dry blotting apparatus [22]. Filters were blocked for 90 min in PBS, pH 7.4, containing $0.05 \%$ Tween and $10 \%$
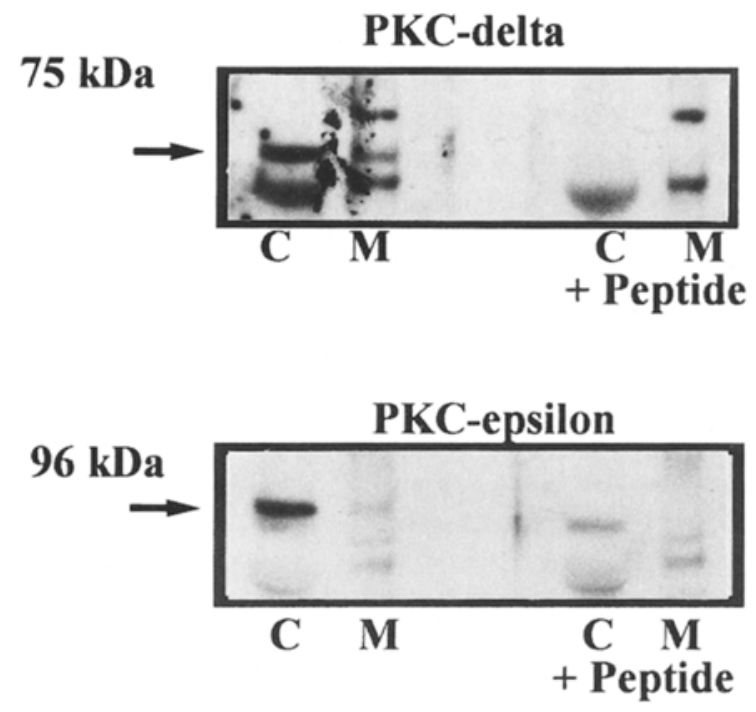

Fig. 1. Immunoblot analysis of PKC isoforms in adult ventricular cardiomyocytes. Cells were lysed and partitioned into cytosol (C) and membrane fraction (M), as described in Methods. $30 \mu \mathrm{g}$ of protein fractions was analysed by SDS/PAGE in a gradient gel (8-18\%), transferred to nitrocellulose and immunoblotted with antisera against PKC-delta and PKC-epsilon. Where indicated, incubations were performed in the presence of the corresponding peptides used for immunisation (see Materials). After incubation with ${ }^{125}$ I-Protein A, the nitrocellulose sheets were subjected to autoradiography

milk powder. Thereafter, filters were incubated for $16 \mathrm{~h}$ at $4{ }^{\circ} \mathrm{C}$ with a $1: 500$ dilution of the GLUT1- or the GLUT4-antiserum, respectively. PKC antisera was used at a dilution of $1: 200$. After extensive washing with PBS containing $0.05 \%$ Tween, filters were incubated for $2 \mathrm{~h}$ with ${ }^{125}$ I-protein A $(0.4 \mu \mathrm{Ci} / \mathrm{ml})$. Filters were again extensively washed, air-dried and exposed to Hyperfilm-MP films using intensifying screens. In addition, blots were detected on a Fujix BAS 1000 Bio-Imaging Analyzer (Fuji, Tokyo, Japan). Quantification was performed on a SPARCstation (Sun Microsystems, Chelmsford, MA, USA) by using image-analysis software.

\section{Statistical analysis}

All data analysis was performed using Fig. P (Biosoft, Cambridge, UK) or t-ease (ISI, Philadelphia, Pa., USA) statistical software. In uptake studies with cultured cells the counts were normalized to the mean protein value calculated from the protein determinations of individual dishes of a certain experiment. The deviation of individual protein values never exceeded $\pm 10 \%$ of the mean. Significance of reported differences was evaluated by using the null hypothesis and $t$ statistics for paired data. Corresponding significance levels are indicated in the Figures.

\section{Results}

Interaction of troglitazone with protein kinase $C$. We have recently reported that activation of $\mathrm{PKC}$ in cardiomyocytes by the phorbolester PMA induces insulin resistance of insulin-stimulated glucose transport 


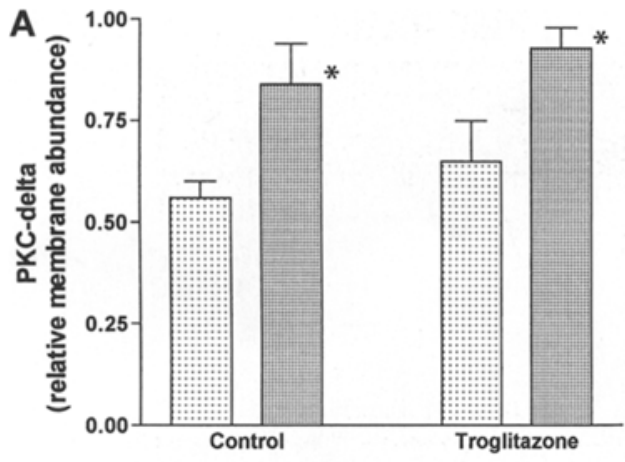

B

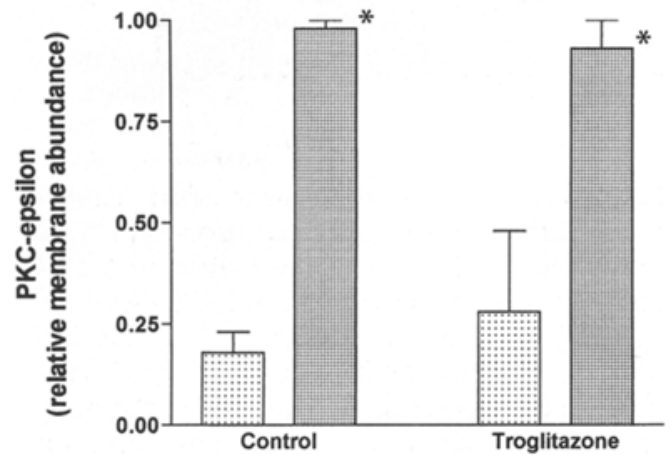

Fig. 2 A, B. Effect of troglitazone on relative membrane abundance of PKC-delta and PKC-epsilon. Cardiomyocytes were exposed for $30 \mathrm{~min}$ to $1 \mu \mathrm{mol} / 1 \mathrm{PMA}$ 掣 in the absence or presence of $5 \mu \mathrm{mol} / \mathrm{l}$ troglitazone. The inactive phorbolester PDD was added to basal cells $\square$. Cytosol and membrane fractions were recovered, analysed by immunoblotting with antisera against PKC-delta (A) or PKC-epsilon (B) followed by incubation with ${ }^{125} \mathbf{I}$-Protein $\mathbf{A}$ and quantification with a bio-imaging analyser. Abundance of PKC-isoforms in membranes is expressed as a fraction of total amount (cytosol + membranes). Data are mean values \pm SEM of four separate experiments. * Significantly different from basal at $p<0.05$

in these cells [16], most probably resulting from an inhibition of the insulin receptor kinase due to enhanced serine phosphorylation of the beta-subunit [23]. In order to evaluate the interaction of troglitazone with PKC in cardiomyocytes we have first identified the isoforms of PKC expressed in these cells. As shown in Figure 1, antiserum against PKC-delta specifically detected a $75-\mathrm{kDa}$ species which was about equally abundant in the cytosol and the membrane fraction. Immunoblots with antiserum against PKC-epsilon revealed a protein with an apparent molecular mass of $96 \mathrm{kDa}$. Under basal conditions this $\mathrm{PKC}$-isoform was nearly exclusively present in the cytosol (Fig. 1). Different antisera against PKC-alpha failed to detect this isoform in adult cardiomyocytes, in agreement with recent findings by Rybin and Steinberg [24]. Since PKC-beta, -gamma and -zeta could not be detected at the protein level $[24,25]$, PKC-delta and -epsilon apparently represent the major isoforms in adult cardiocytes that can be detected with currently available PKC-antibodies.
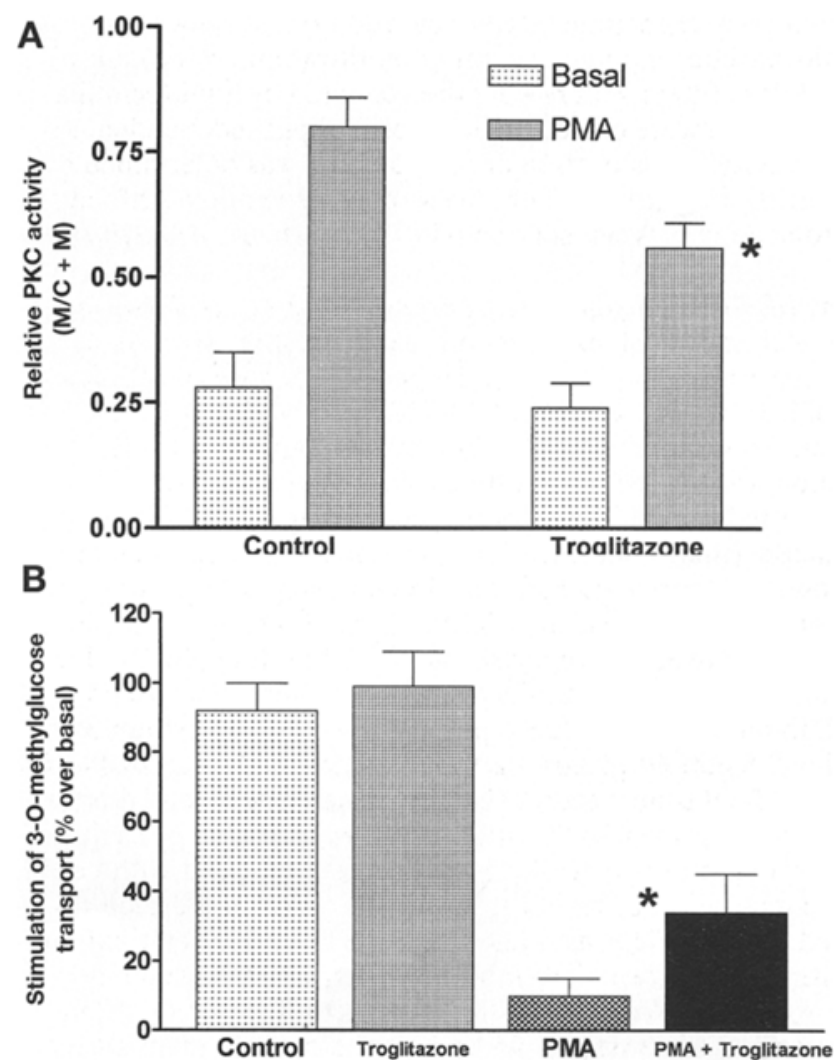

Fig.3. A Effect of troglitazone on membrane-associated PKC activity. Cardiomyocytes $\left(5 \times 10^{5}\right.$ cells $)$ were incubated for $30 \mathrm{~min}$ with $1 \mu \mathrm{mol} / 1 \mathrm{PMA}$ either in the absence (control) or presence of $5 \mu \mathrm{mol} / \mathrm{l}$ troglitazone. PKC was then purified from cytosol (C) and membrane (M) fractions by DEAE-cellulose chromatography and PKC activity was determined as outlined in Methods. Membrane-associated PKC activity is expressed as a fraction of total $(C+M)$ activity. Data reported are mean values \pm SEM of four separate experiments. * Significantly different from control at $p<0.05$. B Effect of troglitazone on PMA-induced desensitization of insulin-stimulated 3 O-methylglucose transport. Cardiomyocytes were incubated for $30 \mathrm{~min}$ in the absence or presence of $5 \mu \mathrm{mol} / \mathrm{l}$ troglitazone, $1 \mu \mathrm{mol} / \mathrm{l}$ PMA, or a combination of the two. After stimulation with insulin $\left(5 \times 10^{-11} \mathrm{~mol} / \mathrm{l}\right)$ for an additional $30 \mathrm{~min}$, transport of 3-O-methylglucose was determined as detailed in Methods. Data are mean values $\pm \operatorname{SEM}(n=3)$. * Significantly different from PMA at $p<0.05$

After a 30-min treatment with PMA a redistribution of both PKC-delta and PKC-epsilon to the membrane fraction could be detected (Fig. 2), with the latter isoform being nearly quantitatively translocated to the membrane (Fig. 2, lower panel). Redistribution of both isoenzymes in response to PMA and under basal conditions was not affected by the presence of troglitazone making it most unlikely that the drug interacts with the regulatory domain of PKC (Fig.2). Determination of membrane-associated PKC activity showed a 2-3 fold increase after PMA treatment (Fig. 3, upper panel). In the presence of troglitazone this stimulatory action was significantly reduced by $43 \pm 4 \% \quad(n=4)$ suggesting that troglitazone may 
inhibit PKC catalytic activity (Fig. 3, upper panel). It should be noted that this drug action was limited to the membrane-associated PKC activity. This effect of troglitazone was then correlated to a putative improvement of insulin action by measuring initial rates of insulin-stimulated 3-O-methylglucose transport in control and PMA-treated cardiomyocytes. As shown in Figure 3 (lower panel), the phorbolester nearly abolished insulin action when determined at physiological concentrations of the hormone $\left(5 \times 10^{-11}\right.$ $\mathrm{mol} / \mathrm{l}$ ), in agreement with our earlier findings [16]. Under these conditions troglitazone produced a significant (about threefold) increase of the insulin response most probably resulting from inhibition of PKC. In order to exclude the possibility that troglitazone acts as a general inhibitor of PKC activity we have used a preparation of PKC from rat brain. At $5 \mu \mathrm{mol} / \mathrm{l}$ the inhibitor bisindolylmaleimide I produced a $90 \%$ inhibition of PKC activity, whereas troglitazone at 5 and $50 \mu \mathrm{mol} / \mathrm{l}$ was uneffective (data not shown). Therefore, the inhibitory action of troglitazone must be related to an isoform- and/or cellspecific pathway.

Acute and chronic effects of troglitazone on glucose transport. In order to test a putative acute stimulation of cardiac glucose transport by troglitazone, freshly isolated cardiomyocytes were incubated for $120 \mathrm{~min}$ with a high concentration of the agent $(50 \mu \mathrm{mol} / \mathrm{l})$ either alone or in combination with insulin $\left(10^{-7} \mathrm{~mol} / \mathrm{l}\right)$. As a control, the cells were incubated in parallel with no addition or in the presence of the hormone. Troglitazone was unable to modify the initial rates of basal and insulin-stimulated 3-O-methylglucose transport (Fig. 4) resulting in an unaltered maximal transport stimulation by the hormone. Similar results were obtained using longer incubation times $(180 \mathrm{~min})$ or a lower concentration $(5 \mu \mathrm{mol} / \mathrm{l})$ of troglitazone (data not shown). In the perfused heart thiazolidinediones have been found to stimulate glycogenolysis and glycolysis secondary to inhibition of oxidative metabolism [26] resulting in a large increase in the release of lactate. We have therefore compared the effects of troglitazone and $\mathrm{NaN}_{3}$, an inhibitor of oxidative phosphorylation, on the release of lactate by freshly isolated cardiomyocytes. The data in Figure 5 clearly show that troglitazone does not modify the release of lactate even after $120 \mathrm{~min}$, whereas $\mathrm{NaN}_{3}$ produces a 2.5 fold increase within 20 min of incubation.

The cells were then transferred to a serum-free primary culture and incubated for $20 \mathrm{~h}$ with increasing concentrations $(0.1$ to $5 \mu \mathrm{mol} / \mathrm{l})$ of troglitazone. 2Deoxy-D- $\left[{ }^{14} \mathrm{C}\right]$ glucose was then directly added to the culture dishes and hexose uptake was monitored over a 90 -min period. As presented in Figure 6 , the chronic exposure to troglitazone produced a dose-dependent increase in 2-deoxyglucose uptake reaching

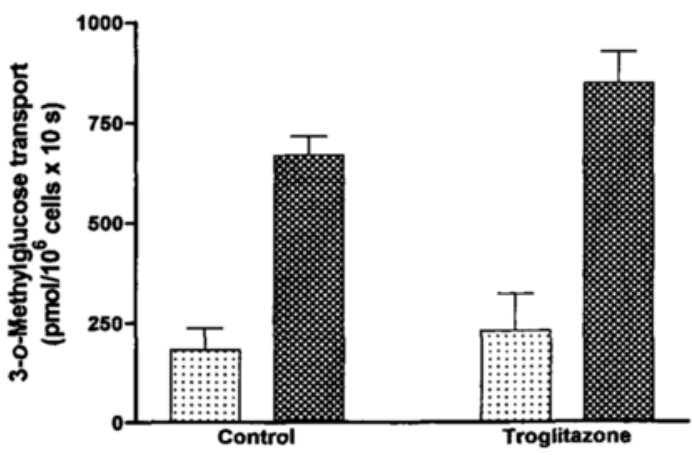

Fig. 4. Basal $\square$ and insulin-stimulated transport of 3-O-methylglucose after acute exposure to troglitazone. Freshly isolated cardiomyocytes $\left(4 \times 10^{5}\right.$ cells $\left./ \mathrm{ml}\right)$ were incubated for $120 \mathrm{~min}$ at $37^{\circ} \mathrm{C}$ either with no addition or in the presence of insulin $\left(10^{-7} \mathrm{~mol} / \mathrm{l}\right)$, troglitazone $(50 \mu \mathrm{mol} / \mathrm{l})$ or a combination of both. The transport of 3-O-methylglucose (final concentration $100 \mu \mathrm{mol} / \mathrm{l}$ ) was then determined over a 10 -s assay period as outlined in Methods. The data shown are mean values \pm SEM obtained from three separate cell preparations

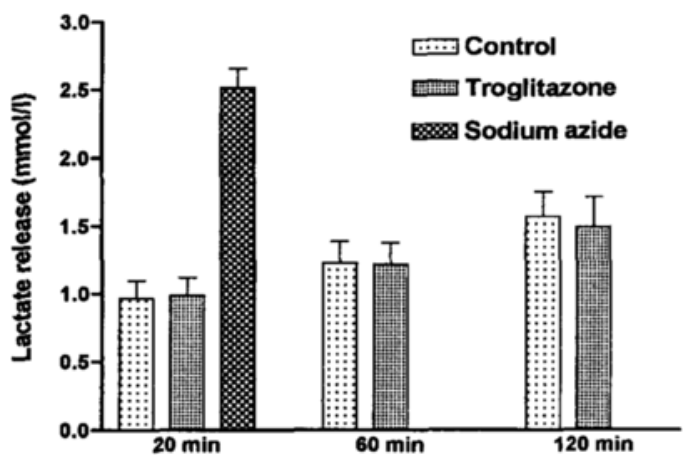

Fig.5. Release of lactate by freshly isolated cardiomyocytes; $2 \times 10^{5}$ cells were incubated in Hepes buffer at $37^{\circ} \mathrm{C}$ for the indicated times in the absence or presence of $5 \mu \mathrm{mol} / 1$ troglitazone or $4 \mathrm{mmol} / 1 \mathrm{NaN}_{3}$. Lactate was determined in the cell supernatant as detailed in Methods. Data reported are mean values $\pm \operatorname{SEM}(n=3)$

a 40 -fold stimulation at $5 \mu \mathrm{mol} / \mathrm{l}$. Under these conditions insulin was unable to further promote glucose uptake by the cardiomyocytes (not shown). It should be noted that neither the viability nor the ATP-content of the cultured cells were affected by the presence of troglitazone and that transport of 2-deoxyglucose represents the rate-limiting step of glucose uptake under all conditions, as previously demonstrated by us for insulin-stimulated 2-deoxyglucose uptake in this cellular system [17].

Regulation of GLUT1 and GLUT4 protein expression by troglitazone. Because troglitazone-stimulated hexose uptake rates were only observed after long-term incubations, we explored a possible effect of the drug on the expression of the glucose transporter isoforms GLUT1 and GLUT4. Immunoblot analysis of crude membrane fractions indicated a dose- 


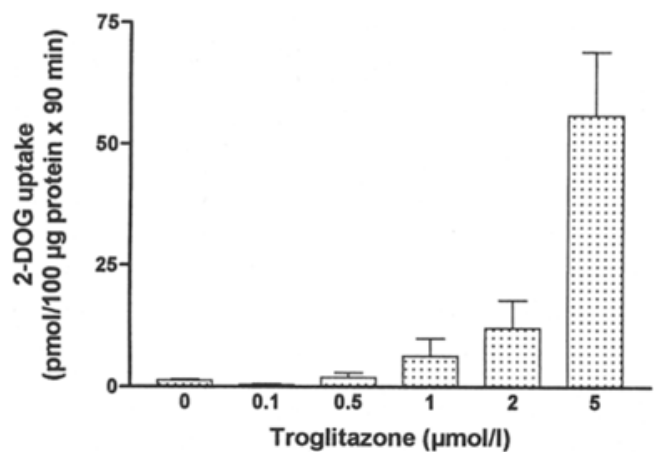

Fig. 6. Dose-dependent chronic effect of troglitazone on 2-deoxyglucose (2-DOG) uptake by cultured adult cardiomyocytes. Cells were kept in serum-free culture for $20 \mathrm{~h}$ in the absence or presence of increasing concentrations $(0.1-5 \mu \mathrm{mol} / \mathrm{l})$ of troglitazone. 2-DOG uptake was then determined by incubating cells with 2 -deoxy-D-[ $\left[{ }^{14} \mathrm{C}\right]$ glucose $(0.4 \mu \mathrm{Ci} / \mathrm{dish})$ for $90 \mathrm{~min}$. The uptake reaction was stopped and quantified as outlined in Methods. Data are mean values \pm SEM of three to five separate experiments

A

GLUT1

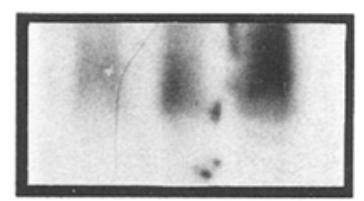

$\begin{array}{llll}\text { Troglitazone } & 0 & 2 & 5\end{array}$

$(\mu \mathrm{mol} / \mathrm{l})$

B

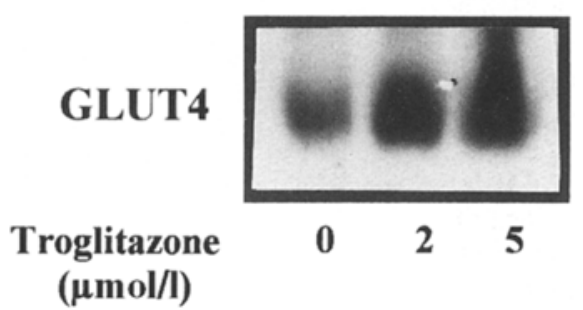

Fig. 7 A, B. GLUT1 and GLUT4 protein expression after chronic exposure to troglitazone. Cardiomyocytes were cultured for $20 \mathrm{~h}$ in the absence or presence of troglitazone ( 2 or $5 \mu \mathrm{mol} / \mathrm{l})$ and processed for preparation of crude membranes as outlined in Methods. Membranes $(15-20 \mu \mathrm{g})$ were resolved by SDS-PAGE, transferred to nitrocellulose and immunodetected with antisera against GLUT1 $(\mathbf{A})$ or GLUT4 $(\mathbf{B})$. The nitrocellulose sheets were incubated with ${ }^{125}$ I-Protein A and submitted to autoradiography. Quantification of signals was performed using image analysis software. Representative blots are shown

dependent, co-ordinated increase of both GLUT1 (molecular mass $49 \mathrm{kDa}$ ) and GLUT4 (molecular mass $54 \mathrm{kDa}$ ) (Fig. 7). When evaluating five independent experiments a significant increase of GLUT1 abundance in response to $5 \mu \mathrm{mol} / \mathrm{l}$ troglitazone could be detected (Fig. 7, upper panel), reaching $320 \pm 80 \%$ of control $(p=0.026)$. The GLUT4

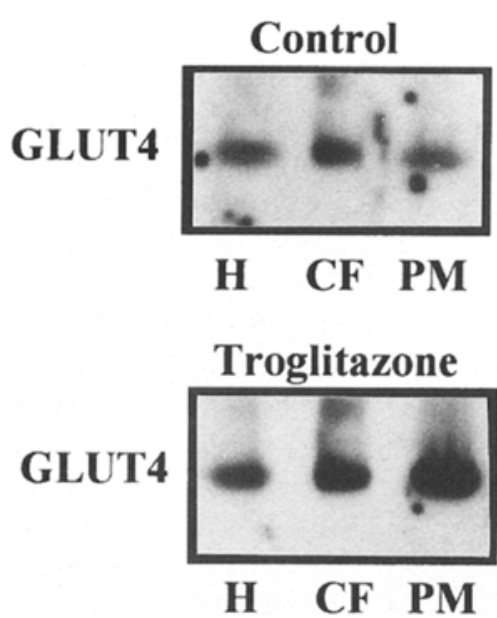

Fig. 8. Effect of troglitazone on plasma membrane GLUT4 abundance. Cells were cultured for $20 \mathrm{~h}$ in the absence (control) or presence of troglitazone and subcellular fractionation was performed as detailed in Methods. 15-20 $\mu \mathrm{g}$ of homogenate $(\mathrm{H})$, crude fraction $(\mathrm{CF})$ or plasma membranes (PM) were separated by SDS-PAGE, transferred to nitrocellulose and immunodetected with antiserum against GLUT4. After incubation with ${ }^{125} \mathrm{I}$-Protein $\mathrm{A}$, the nitrocellulose sheets were subjected to autoradiography

content of cardiomyocytes was less responsive with a significant $(p=0.017)$ increase to $156 \pm 15 \%(n=4)$ of control at $5 \mu \mathrm{mol} / \mathrm{l}$ troglitazone (Fig. 7 , lower panel). It should be noted that the control cells retain a constant level of GLUT4 protein during the $20 \mathrm{~h}$ of culture (data not shown).

Since the increase in total glucose transporter content (fourfold) is insufficient to explain the large stimulation of glucose uptake in response to troglitazone (Fig. 6), we have quantified the abundance of GLUT1 and GLUT4 in the plasma membrane fraction of cardiomyocytes cultured for $20 \mathrm{~h}$ in the presence of troglitazone $(5 \mu \mathrm{mol} / \mathrm{l})$. GLUT1 protein was found to be increased in plasma membranes to $348 \pm 61 \%(n=3)$ of control (data not shown), in agreement with the findings obtained with crude membranes (Fig.7). A representative Western blot for GLUT4 is shown in Figure 8. Both homogenate and crude membrane fraction exhibit a higher GLUT4 content reflecting increased protein expression; however, a considerably higher amount of GLUT4 $(227 \pm 67 \%$ of control, $n=3)$, which even exceeded the increase in GLUT4 expression, could also be detected in the plasma membrane (Fig. 8).

\section{Discussion}

Insulin resistance plays a pivotal role in the pathogenesis of NIDDM [27] and the development of new therapeutic agents that ameliorate insulin resistance has been a major goal of ongoing research. Recently, the thiazolidinedione compound troglitazone has 
gained considerable interest due to a pronounced reduction of hyperinsulinaemia and hyperglycaemia, an improvement of glucose tolerance, and a decrease in insulin resistance in both diabetic animal models [2-5] and patients exhibiting different forms of insulin resistance $[6-8,28]$. In vitro investigations have confirmed that the drug works on skeletal muscle [10], liver [10,11] and adipose tissue [14, 29] most probably involving both a potentiation of insulin action [2,9] and a direct, insulin mimicking effect $[10$, 11]. The present investigation extends these observations to cardiac muscle suggesting that the drug has multiple effects on this target tissue.

A major finding of the present investigation consists in the observation that troglitazone partly antagonizes the PMA-induced activation of PKC. This drug action is of considerable interest since activation of PKC has been implicated in the induction of insulin resistance in all target tissues including cardiac muscle [16], liver [30] and fat [31]. Serine/threonine phosphorylation of the insulin receptor beta-subunit leading to reduced tyrosine kinase activity [23] and modulation of postkinase signalling elements including phosphorylation of insulin-receptor substrate-1 (IRS-1) and reduced activation of phosphatidylinositol 3-kinase [32] most probably underlie this process. Interestingly, glucose apparently represents a physiological activator of PKC [33] and incubation of isolated adipocytes with a high concentration of glucose was shown to induce an inhibition of insulin receptor kinase which could be prevented by PKC-inhibitors [34]. Recently, Kellerer et al. [9] reported that troglitazone antagonizes the glucose-induced inhibition of insulin receptor kinase and at least partly reduces the insulin resistance produced by treatment with phorbolester, leading to the suggestion that troglitazone may function as an inhibitor of PKC. The present investigation confirms these observations and provides direct evidence for an inhibitory action of troglitazone on PKC. At present it has remained unclear which specific PKC-isoform(s) interacts with the insulin signalling cascade. PKC-alpha was shown to reduce insulin stimulation of phosphatidylinositol 3-kinase [32], whereas PKC-beta may play a certain role in insulin signal transduction [33]. As shown here, PKC-delta and PKC-epsilon represent the major isoforms in our preparation of adult ventricular cardiomyocytes, in agreement with the findings of Rybin and Steinberg [24]. It should be noted, however, that Puceat et al. [25] observed expression of PKC-alpha in adult cardiomyocytes. The reason for this difference is unclear at present. It may possibly result from the presence of non-myocyte cells, since it was demonstrated that PKC-alpha can be detected in extracts from whole heart but remains undetectable in extracts from adult cardiomyocytes [24]. In light of the desensitization of insulin-stimulated glucose transport in cardiomyocytes in response to
PMA [16] we conclude that PKC-delta and/or PKCepsilon possibly interfere with insulin action in heart muscle cells. Importantly, the partial inhibition of PKC activity by troglitazone was correlated to a partial restoration of insulin action on glucose transport in PMA-desensitized cardiomyocytes. These data strongly suggest that troglitazone is able to prevent the induction of cardiac insulin resistance resulting from enhanced PKC activity. It may be speculated that inhibition of PKC by troglitazone could be at least one mechanism contributing to the in vivo improvement of insulin resistance observed in animal models and human patients. Obviously, this drug action does not involve the interaction with the regulatory domain of PKC-delta and PKC-epsilon. Furthermore, we have excluded that troglitazone acts as a general inhibitor of catalytic PKC activity. Troglitazone may therefore represent an isoform-specific inhibitor or inhibit PKC by a secondary, cell-specific pathway. This aspect of troglitazone action needs further attention.

A remarkable finding in our study is the observation that troglitazone was unable to modify either basal or insulin-stimulated glucose transport rates using acute treatment protocols. These results suggest that the drug does not directly activate the insulin receptor kinase or down-stream elements of the insulin signalling cascade under normal conditions. This assumption is supported by earlier in vivo investigations showing an unaltered activity of the insulin receptor kinase in muscle tissue of normal control animals treated with troglitazone [12] or pioglitazone [13]. A dual acute effect of troglitazone on glucose uptake by HIT cells was recently reported by Masuda et al. [35]; however, in BC3H-1 myocytes no acute stimulation of glucose uptake could be detected. Thus, we conclude that troglitazone does not act as a rapid, insulin-like activator of muscle glucose uptake. This view is further supported by a completely unaffected release of lactate in the presence of the drug even after $2 \mathrm{~h}$. Further, these data also clearly exclude any effect of the agent on glycogenolysis and glycolysis secondary to an inhibition of oxidative metabolism, as shown for other thiazolidinediones [26].

The data obtained with primary cultured cardiomyocytes clearly show that chronic exposure to troglitazone results in exponential stimulation of glucose uptake with doses between 0.5 and $5 \mu \mathrm{mol} / 1$. It should be noted that the plasma concentration of troglitazone is reported to be between 0.5 and $1 \mu \mathrm{mol} / 1[4$, 11]. At these concentrations glucose uptake was increased 2-4 fold, an effect which is comparable to the sulphonylurea drug glimepiride in this cellular system [18]. We therefore conclude that therapeutic serum concentrations of troglitazone are able to provoke cardiac glucose uptake in diabetic patients. Taking into account the high risk of ischaemic heart disease in diabetic patients, a putative increased glucose 
supply to the cardiomyocyte may exert a cardioprotective function, specifically in regions of partial ischaemia, where anaerobic glycolysis could sustain function and viability of the cardiac cell [36]. Consistently, in a recent report long-term treatment with troglitazone was shown to exert a cardioprotective effect on basal and post-ischaemic cardiac function of diabetic rats through non-insulin-mediated action [37].

It has been reported that cardiac muscle exhibits a much higher basal glucose uptake and GLUT1 content when compared to other muscle tissues [38], suggesting that changes in GLUT1 expression may serve to adjust cardiac glucose metabolism to different metabolic demands [38]. We show here that troglitazone induces a 3-4 fold increase in GLUT1 expression and an approximate doubling of GLUT4. These findings are in good agreement with the chronic effects of troglitazone on 3T3-L1 adipocytes, where the drug increased the basal uptake of glucose about 10-fold and induced an increased expression of both GLUT1 and GLUT4 [14]. Under our conditions the increased expression of glucose transporters may only partly account for the large increase in basal glucose uptake. Additional effects of the drug on the intrinsic activity of the glucose transporters could explain this discrepancy. Indeed, modulation of the intrinsic activity of GLUT2 in HIT cells has been observed by Masuda et al. [35]. Stimulation of GLUT4 expression may have specific impact for the diabetic and/or insulin resistant heart. Thus, we have recently found a $25 \%$ reduction of GLUT4 abundance in cardiac muscle of obese Zucker rats [39] and restoration of GLUT4 content is known to normalize the insulin response in the diabetic heart [40].

Most interestingly, a considerable increase in GLUT4 abundance in the plasma membrane of chronically treated cardiomyocytes could also be detected. This observation suggests that troglitazone in addition to increasing basal glucose uptake by stimulating transporter expression, is also able to redistribute GLUT4 to the plasma membrane in an insulin mimicking fashion. Three lines of evidence support this assumption. First, in the basal state GLUT4 is almost completely sequestered in intracellular tubulovesicular structures found in the trans-Golgi region with only minor amounts in the plasma membrane fraction of ventricular cardiomyocytes [21]; second, the increase in plasma membrane GLUT4 abundance clearly exceeds the increase in GLUT4 expression indicating transporter translocation; third, insulin did not further promote glucose uptake in troglitazonetreated cells suggesting that both agents act on the same pathway. It remains to be clarified if GLUT4 translocation in response to chronic exposure to troglitazone contributes to the hypoglycaemic action of this drug under in vivo conditions.

In summary, our data suggest that troglitazone exerts multiple and potent cardiac actions at the level of the ventricular cardiomyocyte. Modulation of PKC could help to prevent or ameliorate cardiac insulin resistance related to an altered insulin signal transduction. Furthermore, an increased glucose supply resulting from regulation of transporter expression and redistribution by troglitazone may help to improve the performance of the diabetic heart.

Acknowledgements. This work was supported by the Ministerium für Wissenschaft und Forschung des Landes Nordrhein-Westfalen, the Bundesministerium für Gesundheit, and by a grant from Sankyo Europe.

\section{References}

1. Yoshioka T, Fujita T, Kanai T, Aizawa Y, Kurumada T, Hasegawa K (1989) Studies on hindered phenols and analogues. 1. Hypolipidemic and hypoglycemic agents with ability to inhibit lipid peroxidation. J Med Chem 32: 421428

2. Fujiwara T, Yoshioka S, Yoshioka T, Ushiyama I, Horikoshi $\mathrm{H}$ (1988) Characterization of new oral antidiabetic agent CS-045: studies in $\mathrm{KK}$ and ob/ob mice and Zucker fatty rats. Diabetes 37: 1549-1558

3. Fujiwara T, Wada M, Fukuda K et al. (1991) Characterization of CS-045, a new oral antidiabetic agent, II. Effects on glycemic control and pancreatic islet structure at a late stage of the diabetic syndrome in C57BL/KsJ-db/db mice. Metabolism 40: 1213-1218

4. Lee M-K, Miles PDG, Khoursheed M, Gao K-M, Moossa AR, Olefsky JM (1994) Metabolic effects of troglitazone on fructose-induced insulin resistance in the rat. Diabetes 43: 1435-1439

5. Yoshioka S, Nishino H, Shiraki T et al. (1993) Antihypertensive effects of CS-045 treatment in obese Zucker rats. Metabolism 42: 75-80

6. Suter S, Nolan JJ, Wallance P, Gumbiner B, Olefsky JM (1992) Metabolic effects of new oral hypoglycemic agent CS-045 in NIDDM subjects. Diabetes Care 15: 193-203

7. Mimura K, Umeda F, Hiramatsu S et al. (1994) Effects of a new oral hypoglycemic agent (CS-045) on metabolic abnormalities and insulin resistance in type 2 diabetes. Diabet Med 11: 685-691

8. Nolan JJ, Ludvik B, Beerdsen P, Joyce M, Olefsky J (1994) Improvement in glucose tolerance and insulin resistance in obese subjects treated with troglitazone. $\mathrm{N}$ Engl J Med 331: 1188-1193

9. Kellerer M, Kroder G, Tippmer S et al. (1994) Troglitazone prevents glucose-induced insulin resistance of insulin receptor in rat-1 fibroblasts. Diabetes 43: 447-453

10. Ciaraldi TP, Gilmore A, Olefsky JM, Goldberg M, Heidenreich KA (1990) In vitro studies on the action of CS-045, a new antidiabetic agent. Metabolism 39: 1056-1062

11. Murano K, Inoue Y, Emoto M, Kaku K, Kaneko T (1994) CS-045, a new oral antidiabetic agent, stimulates fructose2,6-bisphosphate production in rat hepatocytes. Eur $\mathrm{J}$ Pharmacol 254: 257-262

12. Bader S, Kiehn R, Häring HU (1993) Effect of CS-045 on the activity of insulin-receptor kinase in the skeletal muscle of insulin-resistant Zucker rats. Diabetes und Stoffwechsel 2: 55-61

13. Kobayashi M, Iwanishi M, Egawa K, Shigeta Y (1992) Pioglitazone increases insulin sensitivity by activating insulin receptor kinase. Diabetes 41: 476-483 
14. Tafuri SR (1994) Troglitazone stimulates glucose uptake in 3T3-L1 adipocytes. Diabetes 43 [Suppl 1]: 761 (Abstract)

15. Götzsche O (1986) Myocardial cell dysfunction in diabetes mellitus. Diabetes 35: 1158-1162

16. Russ M, Eckel J (1995) Insulin action on cardiac glucose transport: studies on the role of protein kinase C. Biochim Biophys Acta 1265: 73-78

17. Eckel J, Asskamp B, Reinauer H (1991) Induction of insulin resistance in primary cultured adult cardiomyocytes. Endocrinology 129: 345-352

18. Bähr M, von Holtey M, Müller G, Eckel J (1995) Direct stimulation of myocardial glucose transport and glucose transport-1 (GLUT1) and GLUT4 protein expression by the sulfonylurea glimepiride. Endocrinology 136: 2547-2553

19. Eckel J, Pandalis G, Reinauer H (1983) Insulin action on glucose transport system in isolated cardiocytes from adult rat. Biochem J 21: 385-392

20. Hohorst HU (1963) Enzymatic determination of L-(+)-lactate. In: Bergmeyer HU (ed) Methods of enzymatic analysis. Academic Press, New York, pp 266-270

21. Kolter T, Uphues I, Wichelhaus A, Reinauer H, Eckel J (1992) Contraction-induced translocation of the glucose transporter GLUT4 in isolated ventricular cardiomyocytes. Biochem Biophys Res Commun 189: 1207-1214

22. Wichelhaus A, Russ M, Petersen S, Eckel J (1994) G protein expression and adenylate cyclase regulation in ventricular cardiomyocytes from STZ-diabetic rats. Am J Physiol 267: H548-H555

23. Takayama S, White MF, Kahn CR (1988) Phorbolester-induced serine phosphorylation of the insulin receptor decreases its tyrosine kinase activity. J Biol Chem 263: 3440 3447

24. Rybin VO, Steinberg SF (1994) Protein kinase C isoform expression and regulation in the developing heart. Circ Res 74: 299-309

25. Puceat M, Hilal-Dandan R, Strulovici B, Brunton LL, Brown JH (1994) Differential regulation of protein kinase $\mathrm{C}$ isoforms in isolated neonatal and adult rat cardiomyocytes. J Biol Chem 269: 16938-16944

26. Slieker LJ, Sundell KL, Bush KA, Sage SW, Fitch L, Schmiegel K (1994) Thiazolidinediones stimulate 2-deoxyglucose uptake into G9 myocytes secondary to inhibition of oxidative phosphorylation. Diabetes 43 [Suppl 1]: 399 (Abstract)

27. Häring HU, Mehnert $H$ (1993) Pathogenesis of type 2 (non-insulin-dependent) diabetes mellitus: candidates for a signal transmitter defect causing insulin resistance of the skeletal muscle. Diabetologia 36: 176-182
28. Takino H, Okuno S, Uotani S et al. (1994) Increased insulin responsiveness after CS-045 treatment in diabetes associated with Werner's syndrome. Diabetes Res Clin Pract 24: $167-172$

29. Ohsumi J, Sakakibara S, Yamaguchi J et al. (1994) Troglitazone prevents the inhibitory effects of inflammatory cytokines on insulin-induced adipocyte differentiation in 3T3L1 cells. Endocrinology 135: 2279-2282

30. Takayama S, White MF, Lauris V, Kahn CR (1984) Phorbol ester modulate insulin receptor phosphorylation and insulin action in cultured hepatoma cells. Proc Natl Acad Sci USA 81: 7797-7801

31. Häring HU, Kirsch D, Obermaier B, Ermel B, Machicao F (1986) Tumor promoting phorbol esters increase the $\mathrm{K}_{\mathrm{m}}$ of the ATP-binding site of the insulin receptor kinase from rat adipocytes. J Biol Chem 261: 3869-3875

32. Chin JE, Liu F, Roth RA (1994) Activation of protein kinase $C$ alpha inhibits insulin-stimulated tyrosine phosphorylation of insulin receptor substrate-1. Mol Endo 8: 51-58

33. Draznin B, Leitner JW, Sussman KE, Sherman NA (1988) Insulin and glucose modulate protein kinase $\mathrm{C}$ activity in rat adipocytes. Biochem Biophys Res Commun 156: 570575

34. Farese RV, Standaert ML, Francois AJ et al. (1992) Effects of insulin and phorbol esters on subcellular distribution of protein kinase $\mathbf{C}$ isoforms in rat adipocytes. Biochem $\mathbf{J}$ 288: 319-323

35. Masuda K, Okamoto Y, Tsuura Y et al. (1995) Effects of troglitazone (CS-045) on insulin secretion in isolated rat pancreatic islets and HIT cells: an insulinotropic mechanism distinct from glibenclamide. Diabetologia 38: 24-30

36. Katz AM (1977) Physiology of the heart. Raven, New York

37. Shimabukuro M, Shinzato T, Higa S et al. (1995) Longterm troglitazone treatment preserves cardiac function of streptozotocin-induced diabetic rat. Diabetes 44 [Suppl 1]: 797 (Abstract)

38. Kraegen EW, Sowden JA, Halstead MB et al. (1993) Glucose transporters and in vivo glucose uptake in skeletal and cardiac muscle: fasting, insulin stimulation and immunoisolation studies of Glut1 and Glut4. Biochem J 295: 287-293

39. Uphues I, Kolter T, Goud B, Eckel J (1995) Failure of insulin-regulated recruitment of the glucose transporter GLUT4 in cardiac muscle of obese Zucker rats is associated with alterations of small-molecular-mass GTP-binding proteins. Biochem J 311: 161-166

40. Garvey WT, Hardin D, Juhaszova M, Dominguez JH (1993) Effects of diabetes on myocardial glucose transport system in rat: implications for diabetic cardiomyopathy. Am J Physiol 264: H837-H844 